\title{
E assim criou-se a rede: aspectos técnicos, políticos e epistemológicos envolvidos na criação e desenvolvimento da rede CEDES
}

\author{
Fernando Augusto Starepravo* \\ Leoncio José de Almeida Reis ${ }^{* *}$ \\ Fernando Renato Cavichiolli*** \\ Wanderley Marchi $\mathrm{Jr}^{* * * *}$
}

\begin{abstract}
Resumo: O presente estudo buscou analisar aspectos técnicos, políticos e epistemológicos relacionados ao surgimento e desenvolvimento da Rede Cedes no Brasil, tendo como base documentos, publicações e entrevistas de gestores envolvidos na Rede. A análise nos levou, no limite, a avançar na compreensão das lógicas de funcionamento de dois espaços sociais a princípio distintos ? os campos político/ burocrático e científico/acadêmico ? que passam a se relacionar em função de uma ação do governo federal brasileiro.
\end{abstract}

Palavras-chave: Esporte. Lazer. Políticas públicas. Rede Cedes.

\footnotetext{
'Professor do Departamento de Educação Física da Universidade Estadual de Maringá (UEM) e e do Programa de Pós-Graduação Associado em Educação Física UEM-UEL, Maringá, PR, Brasil. E-mail: fernando.starepravo@hotmail.com

"Professor da Universidade Federal do Paraná (UFPR Litoral), Matinhos, PR, Brasil. E-mail: leojar_edf@yahoo.com.br

".-Professor da Universidade Federal do Paraná (UFPR), Curitiba, PR, Brasil. E-mail: cavicca@ufpr.br

"..*Professor da Universidade Federal do Paraná (UFPR), Curitiba, PR, Brasil. E-mail: marchijr@ufpr.br
} 


\section{INTRODUÇão}

A portaria do Ministério do Esporte $\mathrm{n}^{\circ} 179$, de 20 de outubro de 2011, instituiu a mais recente chamada pública para seleção de projetos de pesquisa a serem desenvolvidos na Rede Cedes, "com a finalidade de estimular a produção do conhecimento fundamentado na pesquisa social e de aperfeiçoar as políticas públicas de esporte e de lazer" (BRASIL, 2011a). Tal iniciativa acabou por gerar toda uma mobilização no meio acadêmico da Educação Física brasileira, mais especialmente naqueles afetos ao "subcampo científico/ acadêmico das políticas públicas de esporte e lazer" (STAREPRAVO, 2011, p. 28).

A Rede Cedes é uma ação programática do Ministério do Esporte que, com estudos balizados por referenciais teóricos originários das ciências humanas e sociais e por meio da interlocução com grupos de pesquisa consolidados e/ou em processo de consolidação - vinculados a instituições de ensino superior e/ou institutos de pesquisa e sociedades científicas -, busca implantar novos grupos de pesquisa e estimular os já existentes a produzir e difundir conhecimentos voltados para a avaliação e o aperfeiçoamento da gestão de políticas públicas de esporte e de lazer (BRASIL, 2009)¹.

Com uma atuação não contínua desde sua criação, em 2003, a Rede Cedes foi responsável pelo apoio a inúmeras pesquisas e publicações nas áreas de esporte, lazer e políticas públicas ${ }^{2}$. Frente sua importância para as pesquisas no subcampo científico/acadêmico das políticas públicas de esporte e lazer, ainda é pequena a atenção dos estudiosos aos mecanismos de constituição e desenvolvimento da Rede, exceção feita ao balanço da Rede Cedes, produzido por um grupo de pesquisadores vinculados à Unesp de Rio Claro (SCHWARTZ et al, 2010), por meio de uma pesquisa encomendada pelo Ministério do Esporte para "atender à demanda do Ministério

\footnotetext{
'BRASIL. Ministério do Esporte. Rede CEDES. Disponível em: <http://portal.esporte.gov.br/ sndel/esporteLazer/cedes/redeCedes.jsp>. Acesso em: 10 ago. 2009.

2Outras informações podem ser consultadas junto ao Repositório Institucional da Rede Cedes (disponível em: <http://www.labomidia.ufsc.br/redecedes/>) e também por meio de obra que avalia a Rede Cedes (SCHWARTZ et al, 2010).
}

Movimento, Porto Alegre, v. 20, n. 01, p. 33-58, jan/mar de 2014. 
do Esporte em relação à organização, sistematização e gestão dos dados referentes aos projetos de pesquisa financiados pela Rede CEDES" (SCHWARTZ et al, 2010, p. 23). A obra supracitada, todavia, apesar de apresentar uma série de contribuições para o entendimento da Rede, não se dedica aos aspectos políticos e epistemológicos que fundamentaram a criação e desenvolvimento da Rede. Esse caso é sintomático de um processo mais geral que ocorre na produção científica do subcampo científico/acadêmico das políticas públicas de esporte e lazer. Há escassez de trabalhos na área de políticas públicas de esporte e lazer que tratem da dimensão arena política no Brasil (AMARAL; PEREIRA, 2009).

Nesse sentido, o presente estudo pretende analisar aspectos técnicos, políticos e epistemológicos relacionados ao surgimento e desenvolvimento da Rede Cedes no Brasil. Para tanto, a metodologia utilizada considerou procedimentos diretos e indiretos. Os procedimentos diretos dizem respeito às entrevistas semi-estruturadas com agentes gestores do Ministério do Esporte diretamente relacionados ao processo de criação, implementação e desenvolvimento da Rede Cedes que ocuparam cargos de segundo e terceiro escalão na estrutura administrativa do ministério. Para garantir o anonimato dos sujeitos de pesquisa não apresentaremos seus nomes, usando códigos para representá-los. Já os procedimentos indiretos foram os da análise documental de alguns documentos disponibilizados por meio do site do Ministério do Esporte. A análise dos dados se deu por meio da análise de discurso (BOURDIEU, 1983, 2000, 2003, 2008)3 e de conteúdo (BARDIN, 1977).

O referencial teórico aqui utilizado é a Teoria dos Campos de Pierre Bourdieu. Para o autor, o estudo dos contextos sociais deve estar relacionado à noção de campo, universos intermediários, com lógicas e dinâmicas de funcionamento próprias. Esses espaços sociais

\footnotetext{
${ }^{3}$ Segundo Bourdieu, é superficial analisar os discursos e as ideologias enfatizando apenas os enunciados, sem considerar a constituição do campo e a relação entre esse campo e o espaço social mais amplo, o qual abrange as posições e os processos sociais. Chama a atenção para a exigência de fundar toda a análise do discurso na construção do campo, no interior do qual esse discurso é produzido e recebido, e observar as organizações distintivas, seus esquemas de produção, reprodução e percepção.
} 
se constituem em função da presença de agentes que compartilham e perpetuam determinados habitus e se relacionam estrategicamente em função de objetos de disputa em comum.

\section{Criação e desenVolvimento de UMA Rede de APOIO À PeSQuisa: O caso da Rede Cedes}

Ao dissertar sobre o surgimento e desenvolvimento da Rede Cedes pelo menos três aspectos precisam ser considerados: o aspecto técnico, o político e o epistemológico. Todos obviamente se relacionam e fica difícil precisar qual deles teve maior relevância quando da criação da Rede. Porém, buscaremos explicitá-los de maneira a romper com a formalidade dos documentos e mergulhar no espaço de relação e interesses dos agentes.

Para entendermos minimamente o aspecto técnico de criação da Rede Cedes, precisamos nos remeter ao processo de formulação do Programa Esporte e Lazer da Cidade (PELC), do qual a Rede Cedes integra o conjunto de ações. A elaboração do PELC, segundo seus idealizadores, não foi aleatória ou apenas pautada no empirismo, práticas recorrentes no "subcampo político/burocrático de esporte e lazer" (STAREPRAVO, 2011, p. 24). Foi uma iniciativa baseada em princípios e conceitos oriundos do espaço social antes ocupado por alguns agentes do ministério, o campo científico/acadêmico. "Pensamos no que um programa guarda-chuva, do ponto de vista das ações, teria que dar conta para efetivamente ser uma política que tivesse como objetivo a universalização do direito ao acesso ao esporte e ao lazer"4. Sob a lógica do planejamento e orçamento governamental, deveria a Secretaria Nacional de Desenvolvimento do Esporte e de Lazer (SNDEL), então responsável pelo programa ${ }^{5}$, propor um grande programa (chamado de "guarda-chuva" pelo gestor), que comportaria em sua rubrica praticamente todas as ações

\footnotetext{
${ }^{4}$ GESTOR D. Entrevista concedida ao autor do presente ensaio, em 29 nov. 2010.

${ }^{5} \mathrm{Hoje}$, o PELC e a Rede Cedes são, teoricamente, de responsabilidade da Secretaria Nacional de Esporte, Educação, Lazer e Inclusão Social, criada posteriormente quando da reestruturação administrativa do Ministério do Esporte, em 2011.
}

Movimento, Porto Alegre, v. 20, n. 01, p. 33-58, jan/mar de 2014. 
da secretaria. Esse grande programa então surgiu configurado de acordo com uma análise situacional, e com base nos procedimentos de um renomado autor do campo acadêmico.

Nesse momento nós nos baseávamos muito num autor [...] do campo do planejamento, que se chamava Carlos Matus [...]. Ele é o precursor do que se chama de planejamento estratégico situacional. O planejamento estratégico dentro do campo governamental. Então nós lidávamos assim com a expressão "nós", que é uma expressão que vem dele. Quais são os "nós" que temos que desamarrar para garantir [...] o acesso universalizado ao esporte e ao lazer? ${ }^{6}$

Os "nós" levantados pela equipe estariam relacionados especialmente à ausência de espaços para a prática esportiva e de lazer, e quando os espaços existiam, por vezes, estavam com pouca manutenção ou então sucateados. Outro "nó" detectado foi a falta de profissionais com formação para atuar com as políticas públicas de esporte e lazer. "Então o que nós pensamos? Que um programa, além de elaborar, oferecer, manter espaços, construir espaços, teria que ter pessoas capazes de atuar nesses espaços"7. O PELC então surge como um programa com vistas à superação dos "nós" detectados, buscando dar conta da disponibilidade de espaços, oportunizar práticas e estimular a reflexão e produção científica sobre o esporte e lazer.

Voltando à Rede Cedes, e ao aspecto técnico de sua criação, este está relacionado à detecção de um "nó" para o desenvolvimento de políticas públicas de esporte e lazer. Trata-se da ausência de formação na área e a consequente falta de profissionais preparados para atuar nesse campo.

[...] não existe no Brasil uma formação específica para isso. As faculdades, os cursos de Educação Física que talvez fosse o local para que isso acontecesse não ocorre. Nós temos uma formação

${ }^{6}$ GESTOR D. Entrevista concedida ao autor do presente ensaio, em 29 nov. 2010. ${ }^{7}$ GESTOR D. Entrevista concedida ao autor do presente ensaio, em 29 nov. 2010.

Movimento, Porto Alegre, v. 20, n. 01, p. 33-58, jan/mar de 2014. 
toda ela voltada para o esporte, para o esporte visando o alto rendimento. $\mathrm{O}$ esporte de lazer, embora esteja lá contemplado na Lei Pelé, [...] quando é visto, é visto de uma forma distorcida ou desvalorizada dentro das próprias universidades ${ }^{8}$.

O PELC deveria então prever, dentre suas ações, algo voltado à produção de conhecimento e à formação de pessoal qualificado para atuar junto ao PELC Projeto Social ${ }^{9}$. A Rede Cedes seria uma das ações com esse intuito, assim como o Cedime (Centro de Documentação e Informação do Ministério do Esporte) e o Prêmio Brasil de Esporte e Lazer de Inclusão Social. Aliás, antes mesmo da criação da Rede Cedes, pensou-se em passar essa atribuição à Rede Cenesp ${ }^{10}$, que necessitaria de uma reformulação, com a ampliação de seu escopo:

Então se pensou uma área de formação. E nós pensamos que essa parte poderia ser dada, subsidiada pela Rede Cenesp. Por quê? Por que era uma coisa que já estava estruturada dentro do ministério, que já tinha colocado recursos dentro da universidade, mas que tinha se voltado apenas para a área biológica ou para a área de alto rendimento. Ou era discussão de qualidade de vida sob o ponto de vista biológico, ou era a parte de alto rendimento, com uma predominância na área fisiológica e biomecânica. Era o que a gente observava na Rede Cenesp. Nós pensamos que essa outra parte de formação de quadros, e de preparação de eventos para fazer a discussão poderia vir por dentro, ser englobado pela Rede Cenesp ${ }^{11}$.

\footnotetext{
${ }^{8}$ GESTOR D. Entrevista concedida ao autor do presente ensaio, em 29 nov. 2010.

${ }^{9}$ Vale relembrar que o PELC surgiu como uma espécie de programa guarda-chuva da SNDEL, que abrange várias ações, dentre elas o Funcionamento de Núcleos do PELC, que será referenciado no texto como o "PELC Projeto Social".

${ }^{10} \mathrm{~A}$ Rede Cenesp é composta por centros de desenvolvimento de pesquisa científica e tecnológica na área do esporte, treinamento e aperfeiçoamento de atletas. Formada pelas estruturas físicas e administrativas, recursos humanos e materiais existentes nas Instituições de Ensino Superior, os Centros de Excelência Esportiva têm como objetivo detectar, selecionar e desenvolver talentos esportivos, especialmente nas modalidades olímpicas e paraolímpicas. (BRASIL, 2008).
}

${ }^{11}$ GESTOR D. Entrevista concedida ao autor do presente ensaio, em 29 nov. 2010.

Movimento, Porto Alegre, v. 20, n. 01, p. 33-58, jan/mar de 2014. 
Após algumas reuniões houve uma negativa por parte da Rede Cenesp, que entendia que essa inserção descaracterizaria a rede. No jogo político estabelecido naquele momento entre o Partido Comunista do Brasil (PCdoB) e o Partido dos Trabalhadores (PT) ${ }^{12}$, e na disputa por legitimidade entre o grupo da SNDEL (com referencial pautado nas Ciências Sociais) e a Rede Cenesp (de referencial das Ciências Biológicas), prevaleceu aqueles que já estavam estabelecidos no campo (Rede Cenesp) e aqueles com maior "potencial de poder" (ELIAS, 2005) no momento (PCdoB), de forma que a Rede Cenesp deixa de estar vinculada ao Departamento de Ciência e Tecnologia da SNDEL, e passa a estar subordinada à SNEAR (Secretaria Nacional de Esporte de Alto Rendimento). Isso, segundo um dos gestores entrevistados, estaria relacionado ainda ao receio de um balanço das realizações da Rede Cenesp até então:

[...] eu queria fazer uma avaliação do que aquela Rede havia produzido até aquele momento, já que havia certo valor de recursos destinados, desde o governo FHC, desde o momento de sua criação até aquele momento e não havíamos encontrado nenhum documento que nos explicasse o destino daqueles recursos, os resultados dos estudos realizados. Isso fez com que eles [membros da Rede Cenesp] se organizassem e chegassem até o Ministro fazendo pleito para que eu não ficasse a frente dessa instância. E essa decisão foi tomada [...] sem o nosso consentimento, da minha equipe ${ }^{13}$.

Essa posição supostamente arbitrária de alterar o lugar da Rede Cenesp na estrutura do ministério teria suscitado como resposta a criação da Rede Cedes. Tem-se aqui a motivação epistemológica, mas também política da criação da nova rede. Se o grupo de agentes da SNDEL aceitasse passivamente aquela situação demonstraria mais uma vez fragilidade no embate dentro do Ministério do Esporte e na busca de legitimidade (BOURDIEU, 1983) no campo.

\footnotetext{
${ }^{12}$ Vale ressaltar que o Ministério do Esporte, desde sua criação em 2003, comportou em sua administração dois partidos distintos, PCdoB e PT. Enquanto o primeiro ficou com a grande parte dos cargos e secretarias do Ministério, ao PT coube a administração apenas da SNDEL. ${ }^{13}$ GESTOR C. Entrevista concedida ao autor do presente ensaio, em 27 out. 2010.
} 
[...] se nós não vamos ficar com a Rede [Cenesp], talvez até seja um problema a menos, a gente cria a nossa rede. Vamos criar outra Rede. [...] Vai ser uma rede para valorizar as questões vinculadas ao esporte recreativo e ao lazer. Ah, como é que nós vamos fazer? Vamos criar a Rede dos centros do desenvolvimento do esporte e do lazer. [...] Nós vamos ser a Rede Cedes ${ }^{14}$.

A passagem acima pode transparecer certo personalismo nas ações públicas, uma vez que a Rede Cedes é tratada como posse de um grupo, a "nossa" rede em detrimento à rede "deles", a Rede Cenesp. Todavia, os dados são insuficientes para afirmarmos categoricamente tal fenômeno, discutido entre outros, por Codato (2002) e Gomes Neto (2009). Outro agente entrevistado aponta para a mesma direção:

Se a excelência esportiva, o alto rendimento foi pra lá, então nós vamos desenvolver uma lógica de Ciência e Tecnologia voltada para os estudos de política esportiva, de gestão esportiva e de lazer, que não a do alto rendimento. Mas a lógica do alto rendimento também trazendo para nós a lógica da gestão do alto rendimento, porque a Rede Cenesp desenvolve estudos de teoria e prática de treinamento esportivo, não da gestão esportiva. E desenvolvemos a Rede Cedes dentro da discussão da construção do PPA, do Plano Plurianual, de novembro ${ }^{15}$.

A disputa política entre os agentes da Rede Cedes e da Rede Cenesp extrapolou inclusive o limite do Ministério do Esporte, estendendo-se a algumas instituições de ensino superior.

[...] a Rede Cedes chega às universidades como chegou também como um elemento político forte de contraponto à Rede Cenesp, porque a Rede Cenesp fazia do grupo vinculado a ela um grupo com status diferenciado nas agências universitárias. A Rede Cedes estabeleceu um equilíbrio de forças

\footnotetext{
${ }^{14}$ GESTOR D. Entrevista concedida ao autor do presente ensaio, em 29 nov. 2010. ${ }^{15} \mathrm{GESTOR}$ C. Entrevista concedida ao autor do presente ensaio, em 27 out. 2010.
} 
políticas. Isso fica muito fácil de constatar na [Universidade A], por exemplo, entre a Rede Cenesp e a Rede Cedes. A Rede Cedes na [Universidade A] surge muito por conta dessa lógica $[\ldots]^{16}$

\section{$\mathrm{O}$ aspecto político de criação da Rede Cedes se manifesta} ainda como estratégia, mesmo não tendo sido citada pelos entrevistados, de sustentação do grupo da SNDEL no Ministério do Esporte. O grupo estava constituído basicamente por agentes oriundos do campo científico/acadêmico ${ }^{17}$ com pouca ou nenhuma inserção no campo político/burocrático ${ }^{18}$. Nesse sentido, a criação da Rede Cedes daria respaldo e sustentação a um grupo de recém chegados, com pouco "capital político" e que ainda não havia internalizado o "habitus" próprio daquele espaço social (BOURDIEU, 1983), como menciona um dos gestores:

Eu nunca me entendi um profissional da política. Nunca pleiteei cargos políticos. E na verdade, os quatro anos que eu passei em Brasília, já agora nesse primeiro governo, a pergunta que muitos me fizeram é como eu fiquei quatro anos sem ter essa inserção partidária em tendências, em grupos políticos, que é o que faz, que sustenta de certa forma quadros dentro de uma estrutura de governo. Eu não tive e não tenho padrinhos políticos para me garantir ${ }^{19}$.

\footnotetext{
${ }^{16}$ GESTOR C. Entrevista concedida ao autor do presente ensaio, em 27 out. 2010.

17"Apesar de Hey (2008) entender o campo como acadêmico, e não científico, uma vez que no Brasil, tem-se mais presente a idéia de academia, com cada área do conhecimento sendo uma espécie de sociedade de caráter científico e com membros próprios, mas que tem um ethos comum global, admite-se aqui o campo como indissociavelmente acadêmico e científico, uma vez que a produção é científica e o meio onde é produzida é acadêmico. O campo científico/ acadêmico é então entendido como o lócus onde ocorrem práticas institucionalizadas de produção do conhecimento, que envolve sobretudo a idéia de universidade" (STAREPRAVO, 2011, p. 59).

${ }^{18} \mathrm{Um}$ espaço que supõe a dissociação da posição e de seu ocupante, da função e do funcionário, do interesse público e dos interesses privados, mas que paradoxalmente funciona como um metacampo do poder, até porque a gênese da ordem pública vem acompanhada da aparição e acumulação de um "capital público" (BOURDIEU, 2005). Cada área no interior do campo político/burocrático, por sua vez, pode ser entendida como um subcampo político/burocrático, onde as especificidades da área de atuação do Estado delimitam o espaço social de atuação dos agentes a ela vinculados.
}

${ }^{19}$ GESTOR C. Entrevista concedida ao autor do presente ensaio, em 27 out. 2010. 
Talvez a resposta para tal indagação seja a sustentação dada pelo espaço social de origem dos agentes, o campo científico/ acadêmico, especialmente através da Rede Cedes, uma vez que a conquista de espaços e permanência em posições estratégicas no campo político/burocrático estão diretamente relacionadas às redes sociais estabelecidas e à posse de capital, especialmente político e cultural (BOURDIEU, 2007b).

Em síntese, e retomando as contribuições de Bourdieu (1983), temos que a caracterização do campo (nesse caso, falamos do Ministério do Esporte, uma estrutura componente do subcampo político/burocrático do esporte e lazer) se dá através da definição do espaço social onde se encontram fixadas as posições, e os agentes sociais movimentam-se objetivando conquistas, além de seu objeto de disputa e seus interesses específicos. Em outras palavras, o campo é definido como "o lócus onde se trava uma luta concorrencial entre os atores em torno de interesses específicos que caracterizam a área em questão" (ORTIZ, 1994, p. 19). Essas disputas, por sua vez, se estabelecem "[...] através dos alvos das lutas entre os dominantes e os pretendentes, as questões a propósito das quais eles se enfrentam, também dependem do estado da problemática legítima" (BOURDIEU, 2007a, p. 64). As disputas em torno da conquista de espaços e estabelecimento de uma agenda de políticas públicas de esporte e lazer no interior do Ministério do Esporte, que envolveu inclusive ações que envolveram a intelectualidade da área, estiveram pautadas, como apontamos, em disputas partidárias, políticas e epistemológicas. Os agentes se movimentaram e atuaram no espaço social, com vistas ao acúmulo de capital e consequente estabilidade na ocupação de espaços. Todo esse intenso movimento político permeou o processo de formulação e implementação de políticas públicas de esporte e lazer durante a primeira década do século XX e gerou, entre outros "produtos políticos", a própria Rede Cedes que será detalhada na próxima etapa do texto. 


\section{FASES DE UMA REDE DE APOIO À PESQUISA: DA INDUÇÃO À DEMOCRA- TIZAÇÃO DO CONHECIMENTO}

Uma vez constituída, a Rede Cedes apresenta, em 2011, como definição formal:

Rede CEDES - denominação representativa genérica para o conjunto de Instituições de Ensino Superior que, por meio de pesquisa social, realiza estudos visando à qualificação das políticas públicas de esporte e lazer de inclusão social. A Rede, fomentada pela Coordenação-Geral de Ciência, Tecnologia e Inovação do Departamento de Planejamento e Gestão Estratégica da Secretaria Executiva, do Ministério do Esporte, tem como objetivos gerar, articular e difundir ações científicas e tecnológicas no campo do esporte e do lazer (BRASIL, 2011b).

A Rede Cedes, ação que integra o PELC, foi implantada como ação programática do Ministério do Esporte, gerenciada pelo Departamento de Ciência e Tecnologia do Esporte, subordinado antes à SNDEL e mais tarde à Secretaria Nacional de Esporte, Educação, Lazer e Inclusão Social. Essa rede reúne Instituições de Ensino Superior (IES) públicas e privadas, que se constituem em núcleos da rede, podendo ser compostos por grupos da mesma instituição ou de instituições diferentes. A Rede Cedes visa estimular esses grupos a produzir e difundir conhecimentos voltados para o aperfeiçoamento e a qualificação de projetos, programas e políticas públicas de esporte recreativo e de lazer, por meio da produção e difusão de conhecimentos fundamentados em referencial oriundo das Ciências Sociais e Humanas (BRASIL, 2011c).

Segundo informações do Ministério do Esporte, pode-se dizer que a Rede Cedes viveu quatro momentos relevantes. O primeiro foi marcado pela concessão de parcerias com grupos de pesquisas de cursos de Educação Física das universidades públicas brasileiras; o segundo, pela ampliação de apoio ao aprofundamento e à consolidação de pesquisas que qualificassem a política de esporte e lazer do país, estendendo, ainda, a possibilidade de parcerias com grupos de estudos de IES particulares; o terceiro momento foi 
marcado pela criação, em 2007, de edital público anual, para a seleção dos projetos a serem apoiados; o quarto momento foi marcado pela ampliação do fomento à pesquisa social sobre políticas públicas de esporte e lazer e pelo investimento na gestão do conhecimento produzido pela Rede Cedes, sua sistematização e socialização (BRASIL, 2011c).

No primeiro momento da Rede Cedes, o que prevaleceu foi a demanda dirigida a grupos de pesquisa já constituídos ou em processo de consolidação que tinham como objeto de estudo as políticas públicas de esporte e lazer.

Os recursos da Rede Cedes seriam destinados por demanda dirigida, por nós dirigida, e aí prevalecia nossos trinta anos de inserção no mundo acadêmico, na busca de desenvolvimento de estudos, de pesquisas que alimentassem a qualificação da gestão pública no campo do esporte recreativo e do $\operatorname{lazer}^{20}$.

O conteúdo das pesquisas, por sua vez, seria encomendado de acordo com as demandas da própria gestão da SNDEL:

Aquilo que nós sentíssemos ausência ou dificuldades da gestão, inexistência de referencial, nós mapeávamos os grupos já existentes, já consolidados, identificávamos aqueles com massa crítica para dar conta do que queríamos, e encomendávamos, fazíamos um contato no sentido de dizer, "olha, identificamos massa crítica para desenvolver tal estudo e precisamos desse estudo. Se vocês concordarem elaborem o projeto, me diga quanto precisam, que nós financiamos o trabalho de vocês" 21 .

A indução pode ser interpretada de maneiras distintas. De acordo com os gestores entrevistados, essa prática estaria relacionada à própria efetividade da rede, uma vez que havia uma necessidade de gestão, e o imperativo de respostas rápidas desencadearia a indução a grupos já com capacidade de pesquisar e dar um retorno sobre aquela demanda.

\footnotetext{
${ }^{20}$ GESTOR C. Entrevista concedida ao autor do presente ensaio, em 27 out. 2010.

${ }^{21}$ GESTOR C. Entrevista concedida ao autor do presente ensaio, em 27 out. 2010.
} 
Eram as induzidas, que era aquilo que nós considerávamos que havia pouco acúmulo dentro da universidade, mas que era fundamental para o desenvolvimento de uma política. Por exemplo, o que nós havíamos detectado? Que a mídia falava muito sobre a questão do financiamento, o financiamento do esporte. Mas não havia um estudo sequer publicado em qualquer base de dados sobre a questão do financiamento do esporte no Brasil. Não tinha um artigo, quiçá um estudo. Então as pessoas estavam falando sobre o financiamento do esporte [...] mas tu não tinha um estudo que desse conta disso. Então ai o que nós fizemos? [...] Nós não temos dados pra dizer quanto é que o Brasil precisa que seja aplicado no esporte. [...] Ora, se não existia eu tinha que induzir. Por que ninguém se interessava dentro da universidade em discutir a questão do financiamento. Não era um tema premente das pessoas de primeira ordem. [...] Nós temos que ter pessoas que pensem nisso, que produzam sobre isso, que façam uma discussão séria sobre isso. Então financiamento é um dos temas que nós vamos induzir ${ }^{22}$.

Sendo essa a motivação da indução parece elogiável a iniciativa, já que rompe com o empirismo e com o senso comum na condução das políticas públicas de esporte e lazer, prática amplamente admitida no subcampo político/burocrático do esporte e lazer (STAREPRAVO, 2011), buscando referenciais científicos para a atuação. Outra condição importante para a indução teria sido a restrição orçamentária. Com poucos recursos, privilegiar-se-iam os grupos nos quais o risco de não ter uma resposta ao investimento fosse menor.

[...] 2004 nós fizemos o primeiro edital da Rede Cedes, foi quando a gente lutou para conseguir o recurso, porque não tinha disponível. A gente foi lá e peitou o ministro, e o ministro liberou um milhão de reais para nós, dos quais nós conseguimos executar $600 \mathrm{mil}^{23}$.

${ }^{22}$ GESTOR D. Entrevista concedida ao autor do presente ensaio, em 29 nov. 2010.

${ }^{23}$ GESTOR D. Entrevista concedida ao autor do presente ensaio, em 29 nov. 2010.

Movimento, Porto Alegre, v. 20, n. 01, p. 33-58, jan/mar de 2014. 
Em se tratando de um programa de tamanha relevância e dada a dimensão das necessidades da gestão, o recurso liberado no primeiro ano de funcionamento da Rede Cedes pode ser considerado ínfimo. Por outro lado, a indução pode ser encarada como um meio utilizado pelo grupo de agentes da SNDEL para demonstrar poder na relação com o campo científico/acadêmico de maneira "oligárquica"24 (ELIAS, 2005). Isso porque a SNDEL estava numa posição privilegiada na relação com os grupos de pesquisa - ou seja, na "correlação de forças" (BOURDIEU, 1993) no campo científico/ acadêmico -, sustentada especialmente pelo capital econômico envolvido.

Nós sempre deixamos isso claro. Quer dizer, não queríamos competir com o CNPQ. O mundo acadêmico que quisesse desenvolver suas pesquisas, seus estudos a partir de seus próprios interesses teria no CNPQ em nível nacional e as agências de fomento estaduais os locais para captar recursos ${ }^{25}$.

E pelo capital científico/acadêmico dos agentes da SNDEL provenientes do campo científico/acadêmico, que lhes conferia legitimidade.

Nesse sentido, nós tivemos uma capacidade política, uma legitimação no mundo acadêmico de fazer uma interlocução de qualidade. [...] Tivemos legitimidade para "peitar" umas disputas por espaço, de quem queria recursos para desenvolver o que bem entendesse. Não, isso aqui é demanda dirigida. Esse teu projeto pode ser interessante, mas não é interessante para nós. Vai buscar o recurso no CNPQ se for o caso ${ }^{26}$.

O subcampo científico/acadêmico das políticas públicas de esporte e lazer, fragilmente constituído naquele momento, por sua vez, parece ter aceitado as demandas por pesquisas, provavelmente pela falta de uma agenda de pesquisa (REIS, 2003) na área, abrindo

\footnotetext{
${ }^{24}$ Em uma situação mais oligárquica, segundo Elias (2005), o equilíbrio de poder a favor do nível mais elevado é muito desproporcional, rígido e estável.

${ }^{25}$ GESTOR C. Entrevista concedida ao autor do presente ensaio, em 27 out. 2010.

${ }^{26}$ GESTOR C. Entrevista concedida ao autor do presente ensaio, em 27 out. 2010.
} 
mão inclusive de parte de sua autonomia. Ressalte-se que nesse momento o recurso da Rede Cedes era exclusivamente voltado às instituições públicas de pesquisa.

[...] nós tínhamos uma coisa assim ó: financiamento público é para entidade pública. Uma das primeiras coisas que a [a gestora que o sucedeu na SNDEL] fez foi abrir o leque [...] Então esses critérios de ser dinheiro público para instituição pública passou batido $^{27}$.

Ou seja, o segundo momento da Rede Cedes, com a inserção de instituições particulares como membros da rede, marca também a temporalidade da saída do grupo da SNDEL, fortemente vinculado ao subcampo científico/acadêmico, que esteve presente desde o governo de transição do presidente Lula na área do esporte. O grupo veio a ser substituído por outro, liderada pela segunda Secretária Nacional da SNDEL. Esta havia sido secretária municipal de esporte e lazer de Porto Alegre por três gestões consecutivas, presidente da Associação Nacional dos Secretários Municipais de Esporte e Lazer (Asmel), e era membro da Setorial de Esporte e Lazer do $\mathrm{PT}^{28}$. Essa transição ocorreu durante o ano de 2006, fruto de supostas acomodações políticas, e das próprias tensões internas à SNDEL e ao PT. "[...] tinha problemas internos de relacionamento e de disputa por espaço político. Nesses quatro anos nós tivemos, eu diria no mínimo uma luta política dentro do partido, dentro da Setorial, por espaço político $[\ldots]^{\prime 29}$.

A frágil relação entre o grupo do PT e o grupo de agentes do $\mathrm{PCdoB}$, que naquele momento também passava por reformulações, com a mudança de ministro, igualmente haveria contribuído para as mudanças na SNDEL:

\footnotetext{
${ }^{27}$ GESTOR D. Entrevista concedida ao autor do presente ensaio, em 29 nov. 2010.

${ }^{28} \mathrm{Os}$ Setoriais são estruturas previstas no estatuto do partido integradas por filiados que atuam em determinada área específica, com o objetivo de intervir partidariamente junto aos movimentos sociais organizados. Os Setoriais podem se organizar em âmbito municipal, estadual ou nacional, mediante autorização das instâncias de direção correspondentes. O Setorial de Esporte e Lazer no PT está vinculado à Secretaria de Movimentos Populares.
}

${ }^{29}$ GESTOR C. Entrevista concedida ao autor do presente ensaio, em 27 out. 2010.

Movimento, Porto Alegre, v. 20, n. 01, p. 33-58, jan/mar de 2014. 
Por que nós tínhamos com o [Ministro do Esporte] autonomia. E quando o [novo Ministro] assume, e nos chama para conversar, nesse momento que o [Ministro do Esporte] sai para concorrer ao senado pelo Distrito Federal [...] o [novo Ministro] nos chama e diz: olha o negócio é o seguinte, esse negócio de autonomia pra mim não serve. A partir de agora é o seguinte: eu sou bem estalinista, usou exatamente essa expressão. Nesse caso, nessa questão eu sou bem stalinista, tem que ser disciplinado. Quer dizer, se o Ministro determina, cumpra-se. [...] Eu disse: está bom. Não tem problema nenhum. [...] mas nós continuamos agindo da mesma forma. Claro que isso foi deixando muito bravo o ministro ${ }^{30}$.

Toda essa situação levou o novo ministro do esporte, a trazer para a SNDEL agentes supostamente mais alinhados a sua maneira de atuar.

[...] isso acaba fazendo com que após quase quatro anos, o Ministro, já nesse momento o [novo Ministro], ele se aproveite disso pra levar à Secretaria de Desenvolvimento de Esporte e Lazer uma pessoa que ele tinha mais afinidade e que era, digamos assim, mais próxima dele do ponto de vista dos seus interesses ${ }^{31}$.

Posição essa em partes corroborada por um dos agentes que compuseram esse novo grupo dirigente da SNDEL:

Claro que teve a indicação do partido, teve um aceite do ministro [...] Então assim, ocupação do espaço público em governos democráticos e populares não se dá só por indicação ou por amizade, se dá por uma série de fatores, entre eles, a ocupação na militância. Não necessariamente a militância no partido que havia, mas somada a uma militância no teu trabalho identificado com o governo ${ }^{32}$.

\footnotetext{
${ }^{30}$ GESTOR D. Entrevista concedida ao autor do presente ensaio, em 29 nov. 2010.

${ }^{31}$ GESTOR D. Entrevista concedida ao autor do presente ensaio, em 29 nov. 2010.

${ }^{32}$ GESTOR B. Entrevista concedida ao autor do presente ensaio, em 26 mar. 2010.
}

Movimento, Porto Alegre, v. 20, n. 01, p. 33-58, jan/mar de 2014. 
O terceiro momento da Rede Cedes se inicia quando, em 2007, o ministério passa a selecionar as pesquisas e grupos a partir de edital público, abandonando parcialmente a prática do convite a grupos de pesquisa. Esse procedimento parece constituir um avanço no tratamento do Ministério do Esporte com o subcampo científico/ acadêmico, uma vez que possibilita a concorrência de novos agentes e instituições com aqueles já estabelecidos no subcampo, pretensiosamente a partir de critérios técnicos, e resgata parte da autonomia dos pesquisadores e grupos de pesquisa que passam a ter maior flexibilidade para propor suas pesquisas.

O edital oportuniza que as pessoas, ao mesmo tempo, no mesmo horário, façam a inscrição, que a seleção possa ser feita de maneira depois comparativa e hierarquizada. [...] Fora isso, exigiu que os próprios proponentes fizessem projetos melhores, porque eles tinham que concorrer. Não era só chegar, apresentar qualquer projeto e ganhar a verba. A partir do momento que tem que concorrer, se o outro é melhor do que o teu, e o edital for sério e fazer justiça, tu pode ser meu melhor amigo, tu não vai levar. [...] acho que garante um nível de transparência, na questão que deve ser o poder público, com suas verbas, também uma credibilidade para as pesquisas, e uma busca de melhoria na questão dos pesquisadores, procurar fazer bons projetos, qualificar os seus projetos ${ }^{33}$.

Porém, esses editais não são totalmente abertos, uma vez que a SNDEL traçou linhas de pesquisa onde os projetos que concorressem aos editais deveriam se encaixar. Isso seria justificado mais uma vez pela restrição orçamentária da secretaria e pela necessidade de subsídios científicos à formulação de políticas públicas na área.

Como nós não temos como garantir [o financiamento de] qualquer pesquisa no sentido que todas as pesquisas têm valor, e [...] como nós não somos uma agencia fomentadora. Estamos, digamos,

${ }^{33}$ GESTOR B. Entrevista concedida ao autor do presente ensaio, em 26 mar. 2010.

Movimento, Porto Alegre, v. 20, n. 01, p. 33-58, jan/mar de 2014. 
auxiliando nesse aspecto. A nossa pesquisa ela tem linhas de possibilidades de maior aplicabilidade nas políticas públicas de esporte e lazer. Quando tu define essas linhas, tu já deixa claro para as pessoas o que está precisando. Os que posteriormente, em breve, serão utilizados. Por que nós estamos precisando, senão não estaríamos encomendando essas pesquisas.

As linhas de pesquisa, por sua vez, eram definidas pelos próprios pesquisadores que já participavam da rede (KAWAGUTI, 2010), fato esse que coloca em cheque a possibilidade de igualdade de condições entre os postulantes a núcleo da rede e aqueles já estabelecidos no espaço social. Além disso, a indução direta de pesquisas não foi abolida da Rede Cedes, como indica um dos gestores:

As pesquisas elas são conveniadas por dois moldes: ou semi-induzidas por um edital que determina as linhas a serem inscritas, que vão orientar as inscrições dos projetos, ou induzida. O que significa induzida? A Secretária, após a seleção pelo edital, ela faz o balanço: que demandas estão postas pela Política Nacional que não foram inscritas no edital? Então nós vamos convidar universidades para atuar nessas demandas ${ }^{34}$.

Apesar da justificativa técnica, o novo grupo de agentes da SNDEL recorre naquilo que havia apontado como limitação do grupo que os antecedeu, a indução que pode colocar em dúvida os critérios de seleção dos núcleos da Rede, bem como ferir a autonomia do subcampo científico/acadêmico em fazer valer sua agenda de pesquisa. Seriam exemplos de indução as pesquisas junto a comunidades indígenas, estudos voltados à Copa do Mundo de Futebol masculino (KAWAGUTI, 2010), e ainda a efetividade do chamado Estatuto do Torcedor.

Outra novidade que surgiu no decorrer do desenvolvimento da Rede Cedes foi o consórcio de grupos de pesquisa. "[...] o edital deu um passo quando os próprios pesquisadores criaram categorias no

${ }^{34}$ GESTOR A. Entrevista concedida ao autor do presente ensaio, em 25 mar. 2010.

Movimento, Porto Alegre, v. 20, n. 01, p. 33-58, jan/mar de 2014. 
edital, podendo você escrever como um grupo de pesquisa somente, como um consórcio de grupos, consorciante com instituições maiores" ${ }^{35}$. Assim, instituições de diferentes regiões do país poderiam estabelecer parcerias e realizar pesquisas em conjunto. Segundo os agentes entrevistados essa foi uma iniciativa que proporcionou bons frutos à rede. As categorias do edital de 2009, por exemplo, foram estabelecidas de acordo com o montante financeiro solicitado para a pesquisa, que crescia de acordo com o envolvimento de diferentes pesquisadores, grupos e instituições, no sentido de privilegiar a coletividade nas pesquisas ${ }^{36}$.

Em relação ao quarto momento da Rede Cedes, de balanço e divulgação da produção científica, destaca-se a iniciativa de difusão e democratização do conhecimento produzido. Dentre suas estratégias de ação, ressalta-se a criação de um sistema de rede online de informações, denominado Repositório Institucional da Rede Cedes, o qual congrega as instituições, os grupos de pesquisa e sociedades científicas que partilham as ações da rede, permitindo ampla troca de informações e dos conhecimentos produzidos por meio digital. Nesse sistema são inseridos os projetos, os relatórios e toda a produção científica proveniente dos projetos financiados pela Rede Cedes, mostrando-se como uma importante ferramenta de disseminação do conhecimento (NAZÁRIO, 2010). A criação do Repositório estaria relacionada ainda à difusão do conhecimento e apropriação pelos agentes do subcampo político/burocrático do esporte e lazer.

Então nós estamos criando o repositório digital, onde será disponibilizado, aberto, com acesso ao público. E vários outros mecanismos para que ela volte aos programas sociais, a sociedade como um todo, de forma a qualificar essas práticas ${ }^{37}$.

\footnotetext{
${ }^{36}$ Categoria 1 - pesquisas no valor de até $R \$ 25.000,00$ apresentadas por um pesquisador; categoria 2 - pesquisas no valor de até $R \$ 60.000,00$, apresentada por um Núcleo, ou seja, por mais de um grupo de estudo da mesma instituição proponente; categoria 3 - pesquisas no valor de até $R \$ 100.000,00$, coordenada por uma instituição proponente, envolvendo a parceria de grupos de estudos de, pelo menos, duas instituições de ensino superior diferentes (BRASIL, 2009).
}

${ }^{37}$ GESTOR A. Entrevista concedida ao autor do presente ensaio, em 25 mar. 2010.

Movimento, Porto Alegre, v. 20, n. 01, p. 33-58, jan/mar de 2014. 
Todavia vale destacar que a simples disponibilização de conteúdo online não resolverá o problema da difusão e incorporação do conhecimento. Deve estar articulado a um conjunto de ações que envolva a formação básica e continuada dos agentes, distribuição de material impresso, além de outros meios mais acessíveis àqueles que vêm conduzindo e operacionalizando as políticas públicas de esporte e lazer no país.

Em síntese, pode-se dizer que a Rede Cedes vem mobilizando grupos de pesquisa em várias regiões do país no sentido de pesquisar temáticas correlatas às políticas públicas de esporte e lazer, seja de maneira induzida ou por meio de editais públicos, envolvendo pesquisadores, estudantes e técnicos, e que o resultado das pesquisas vem sendo divulgado em distintos meios de disseminação científica, o que por sua vez, até o momento, não parece ter garantido a democratização do conhecimento produzido, uma vez que a circulação do conhecimento produzido na Rede sugestiona ter sido bastante endógena.

Nessa etapa do texto, quando deslocamos o foco da politics para a policy ${ }^{38}$, a análise toma ares mais técnicos, com base nos documentos, depoimentos e análises já empreendidas sobre a Rede Cedes. Porém, não devemos perder de vista que a concretude das ações de implementação e desenvolvimento da Rede estão pautadas e permeadas pela dinâmica do espaço social, que a esse ponto envolve, entre outras estruturas, o Ministério do Esporte e seus gestores, as universidades e seus pesquisadores, além de órgãos de fomento a pesquisa como o CNPq. Referimo-nos nesse momento, portanto, a um espaço social de intersecção, estabelecido a partir da criação da Rede Cedes, que envolve dois espaços sociais distintos, os subcampos político/burocrático do esporte e lazer e o científico/ acadêmico das políticas públicas de esporte e lazer, cada qual com sua lógica, dinâmica e objetos em disputa próprios. Como síntese dessa relação entre os espaços sociais, temos as (re) configurações

\footnotetext{
${ }^{38} \mathrm{Na}$ língua portuguesa a palavra política pode ter variadas conotações, que no fundo se referem a diferentes etapas do processo político. Na língua inglesa, há diferenciação, através dos termos polity, politics e policy. Sumariamente, o primeiro termo designa as instituições políticas; o segundo, os processos políticos; e o último os conteúdos da política (FREY, 2000).
} 
da Rede Cedes, que exprimem entre outras questões a ampliação ou direcionamento do financiamento público, a restrição ou ampliação das possibilidades de inserção na Rede, a garantia ou não da autonomia dos pesquisadores em estabelecer uma agenda de pesquisa ${ }^{39}$ para a área, e a possibilidade de formação de redes de pesquisa e difusão do conhecimento.

Essas questões, expressas nas diferentes etapas sublinhadas da Rede Cedes, tomaram rumos distintos daqueles traçados a princípio pelos agentes que implantaram a Rede. Isso porque, vale ressaltar, que "nada é mais difícil e até mesmo impossível de 'manipular' do que um campo" (BOURDIEU, 2004, p. 25). Por maior que seja o peso do agente no interior do campo, é difícil pensar, a partir de um olhar maquiavélico do processo, que um agente singular tenha a capacidade de manipular e conformar o campo ou seus processos de acordo exclusivamente com seus anseios. Isso está submetido às regras do campo, no qual esses interesses serão resignificados e poderão gerar conseqüências não planejadas. $\mathrm{Na}$ concepção de Elias (2005), à medida que se entrecruzam as jogadas de inúmeros jogadores interdependentes, nenhum jogador isolado ou grupo de jogadores, atuando sozinhos, poderão determinar o decurso do jogo. Este fenômeno é caracterizado por Elias (2005) como o processo cego ou opacidade da configuração (ou campo na concepção bourdiana).

\section{Considerações FinaIs}

O balanço dos projetos financiados pela Rede Cedes, realizado por Kawaguti (2010), aponta que foram firmados 129 convênios, envolvendo 208 pesquisas, as quais mobilizaram mais de 1000 pesquisadores e tiveram o subsídio de mais de 500 auxílios financeiros em forma de bolsa. Por outro lado, afirma que não foi possível identificar o montante total concedido pela Rede Cedes e os valores de contrapartida oferecidos pelas instituições, bem como o número

\footnotetext{
${ }^{39}$ Entendendo o termo como "um programa de trabalho que define uma comunidade científica" (REIS, 2003, p. 12).
} 
exato de pesquisadores envolvidos, haja vista a inconsistência dos dados nos relatórios oficiais. De toda forma, os dados apontam a dimensão e importância da Rede, que conta ainda com repercussões imensuráveis em termos políticos e simbólicos.

Nesse sentido, o presente estudo buscou analisar aspectos técnicos, políticos e epistemológicos relacionados ao surgimento e desenvolvimento da Rede Cedes no Brasil, tendo como base documentos, publicações e entrevistas de gestores envolvidos na Rede. Pudemos constatar que o surgimento da Rede se deu em meio a um movimento político intenso, especialmente dentro do Ministério do Esporte, mas que também repercutiu nas universidades envolvidas na Rede. Houve ainda motivações técnicas relativas às carências observadas no subcampo político/burocrático do esporte e lazer, bem como embates epistemológicos redundantes ao campo da educação física nacional. O desenvolvimento da Rede Cedes, por sua vez, se caracteriza em etapas distintas e não lineares de aperfeiçoamento, que repercutiram interesses e anseios dos gestores e pesquisadores envolvidos na Rede.

Não obstante, a análise do surgimento e desenvolvimento da Rede Cedes nos leva, no limite, a avançar na compreensão das lógicas de funcionamento de dois espaços sociais a princípio distintos - os campos político/burocrático e científico/acadêmico - que passam a se relacionar em função de uma ação do governo federal brasileiro.

A despeito dos ganhos individuais e de grupos vinculados à Rede, cumpre observar que a relação entre os campos pode servir para qualificar a pesquisa e a atuação no âmbito das políticas públicas de esporte e lazer no Brasil, ainda tão carente de qualidade e referenciais. Nesse sentido, cabe a todos envolvidos na Rede Cedes trabalhar e cobrar o aperfeiçoamentos da Rede, especialmente no que diz respeito à superação na descontinuidade das ações, e na liberação imediata dos recursos contingenciados pelo Ministério do Esporte no edital da Rede Cedes de 2011. Cabe ressaltar nessa direção a mobilização de um grupo de pesquisadores da Rede Cedes e do Colégio Brasileiro de Ciências do Esporte (CBCE), que vem se articulando desde o início de 2012 junto ao Ministério do Esporte 
com vistas a rediscutir e re-estruturar a Rede Cedes, sugerindo o reconhecimento, por parte da comunidade acadêmica e do Ministério do Esporte, da importância da manutenção e ampliação da Rede. 
And thus created to network: technical, political and epistemological aspects involved in creating and development of the network CEDES Abstract: This study investigates the technical, political and epistemological aspects related to the emergence and development of the Network Cedes in Brazil, based on documents, publications and interviews with managers involved in the Network. The analysis led us, ultimately, to advance the understanding of the logical operation of two distinct social spaces in the beginning - to the political / bureaucratic and scientific / academic - who now relate on the basis of one share of the Brazilian federal government.

Key words: Sports. Leisure. Public policy. Network Cedes.

\footnotetext{
Y así creó a la red: aspectos técnicos, políticos y epistemológicos involucrado en la creación y desarrollo de la red CEDES

Resúmen: Este estudio investiga los aspectos técnicos, políticos y epistemológicos relacionados con el surgimiento y desarrollo de la Red Cedes en Brasil, basado en documentos, publicaciones y entrevistas con los directores que participan en la red. El análisis nos llevó, en última instancia, avanzar en la comprensión de la operación lógica de dos espacios sociales distintos, en principio - a la política / burocrática y científica / académica - que ahora se relacionan sobre la base de una acción del gobierno federal de Brasil.

Palabras-clave: Deportes. Ócio. Políticas públicas. Rede Cedes.
}

\section{REFERÊNCIAS}

AMARAL, S. C. F; PEREIRA, A. P. C. Reflexões sobre a produção em políticas públicas de Educação Física, esporte e lazer. Revista Brasileira de Ciências do Esporte, Campinas, v. 31, n. 1, p. 41-56,2009.

BARDIN, L. Análise de conteúdo. Lisboa: Edições 70, 1977.

BOURDIEU, P. A casa do rei à razão de Estado: um modelo da gênese do campo burocrático. In: WACQUANT, L. O mistério do ministério - Pierre Bourdieu e a política democrática. Loïc Wacquant (Org.) - Rio de Janeiro: Revan, p. 41-70, 2005. 
BOURDIEU, P. O campo econômico: a dimensão simbólica da dominação. Tradução de Roberto Leal Ferreira; revisão técnica Daniel Lins. Campinas: Papirus, 2000.

BOURDIEU, P. A distinção: crítica social do julgamento. São Paulo: Edusp, 2008.

BOURDIEU, P. Espíritos de Estado: gênese e estrutura do campo burocrático. In: BOURDIEU, P. Razões práticas: sobre a teoria da ação. Tradução de Mariza Corrêa. Campinas: Papirus, p. 91-135, 2007b.

BOURDIEU, P. Por uma ciência das obras. In: BOURDIEU, P. Razões práticas: sobre a teoria da ação. Tradução de Mariza Corrêa. Campinas: Papirus, p. 53-90, 2007a.

BOURDIEU, P. Questões de sociologia. Rio de Janeiro: Marco Zero, 1983.

BOURDIEU, P. Os usos sociais da ciência: por uma sociologia clínica do campo científico. Texto revisto pelo autor com a colaboração de Patrick Champagne e Etienne Landais; Tradução de Denice Barbara Catani. São Paulo: Editora UNESP, 2004.

BOURDIEU, P. (Coord.). Miséria do mundo. 5. ed. Tradução de Mateus S. Soares Azevedo. Petrópolis: Vozes, 2003.

BRASIL. Ministério do Esporte. Portaria no 179, de 20 de outubro de 2011. Brasília, 2011a.

BRASIL. Ministério do Esporte. Seleção para apoio a projetos de pesquisa com vistas ao desenvolvimento do esporte e do lazer. Brasília, 2011b.

BRASIL. Ministério do Esporte. Rede CEDES. Disponível em: <http:// portal.esporte.gov.br/sndel/esporteLazer/cedes/redeCedes.jsp>. Acesso em: 10 ago. 2009.

BRASIL. Ministério do Esporte. Portal da Copa. Apresentação. Disponível em: <http://www.esporte.gov.br/sndel/esporteLazer/cedes/apresentacao.jsp>. Acesso em: 4 abr. 2011c.

BRASIL. Ministério do Esporte. Portal da Copa. [Rede CENESP]. Disponível em: <http://portal.esporte.gov.br/snear/cenesp/default.jsp>. Acesso em: 30 ago. 2008.

CODATO, E. Personalismo político nos anos cinqüenta. Revista de História Regional, Ponta Grossa, v. 7, n. 1, p. 9-45, 2002.

ELIAS, N. Introdução à sociologia. São Paulo: Edições 70, 2005.

FREY, K. Políticas públicas: um debate conceitual e reflexões referentes à prática da análise de políticas públicas no Baril. Planejamento e Políticas Públicas, Brasília, n. 21, p. 211-259, jun. 2000. 
GOMES NETO, J. M. W. Instituições e accountability na teoria democrática contemporânea. Revista de Estudos Constitucionais, Hermenêutica e Teoria do Direito, São Leopoldo - RS, v. 1, n. 1, p. 56-64 2009.

HEY, A. P. Esboço de uma sociologia do campo acadêmico: A educação superior no Brasil. São Carlos - SP: EdUFSCar, 2008.

KAWAGUTI, C. N. Análise dos projetos financiados pela Rede Cedes. In: SCHWARTZ, G. M. et al. Gestão da informação sobre esporte recreativo e lazer: balanço da Rede Cedes. Várzea Paulista: Fontoura, 2010.

NAZÁRIO, M. E. dos S. Contextualização histórica da Rede Cedes. In: SCHWARTZ, G. M. et al. Gestão da informação sobre esporte recreativo e lazer: balanço da Rede Cedes. Várzea Paulista: Fontoura, 2010.

ORTIZ, R. Pierre Bourdieu. São Paulo: Ática, 1994.

REIS, E. P. Reflexões legais para a formulação de uma agenda de pesquisa em políticas públicas. Revista Brasileira de Ciências Sociais, São Paulo, v.18, n. 51, p. 11-14, fev. 2003.

SCHWARTZ, G. M. et al. Gestão da informação sobre esporte recreativo e lazer: balanço da Rede Cedes. Várzea Paulista: Fontoura, 2010.

StAREPRAVO, F. A. Políticas públicas de esporte e lazer no Brasil: aproximações, intersecções, rupturas e distanciamentos entre os subcampos político/burocrático e científico/acadêmico. Tese (Doutorado em Educação Física) - Universidade Federal do Paraná, Curitiba, 2011.

Endereço para correspondência:

Fernando Augusto Starepravo

Universidade Estadual de Maringá

Departamento de Educação Física

Avenida Colombo, 5.790, Campus Universitário

Fone: (044) 3011-4315

CEP 87.020-900

Maringá-PR

Recebido em: 17.06.2012

Aprovado em: 29.04.2013 